\title{
HACIA LA SUPERACIÓN DE LAS CONDICIONES LABORALES DEL TRABAJO SOCIAL: RELACIÓN ENTRE LOS DERECHOS HUMANOS, LA ÉTICA PROFESIONAL Y LAS ESTRATEGIAS DE TRANSFORMACIÓN
}

\author{
Iván de Jesús Rosa', \\ Luis Ortiz Mojica², \\ Leticia Gayol Santana ${ }^{3}$, \\ Ana D. Cruz Sánchez ${ }^{4}$ \\ Francisco J. González Parés ${ }^{5}$
}

\section{Resumen}

En el contexto del neoliberalismo, la formulación e implementación de políticas sociales presenta un serio desafío para la práctica del trabajo social. La finalidad de este estudio fue examinar estrategias concretas para mejorar las condiciones laborales actuales de los profesionales del Trabajo Social en función de una práctica ética y garante de derechos humanos. Utilizando un enfoque cualitativo, el análisis se realizó partiendo de las siguientes categorías: (a) condiciones laborales precarizadas y derechos humanos, (b) ética en propuestas esbozadas, y (c) acciones del gremio para mejorar las condiciones laborales. El análisis de estas categorías proyectó una trasgresión sistemática de los derechos humanos de la ciudadanía de parte del Estado, diversos posicionamientos éticos de parte de los profesionales del Trabajo Social para hacerle frente a la neoliberalización de la política social, y una multiplicidad de alternativas para atender la desprofesionalización, las cuales respondían a los respectivos posicionamientos éticos de los/as profesionales. [Palabras clave: condiciones laborales, Trabajo Social, ética profesional, proyecto ético-político profesional, derechos humanos].

\section{Abstract}

In the context of neoliberalism the formulation and implementation of social policies presents a serious challenge for professional practice. The purpose of the study was to examine concrete strategies to improve current working conditions of professional social workers in terms of ethical practice and guarantor of human rights. Using a qualitative approach, the analysis was realized on the basis of the following categories: (a) precarious working conditions and human rights, (b) ethics in proposals outlined, and (c) actions of the guild to improve working conditions. The analysis of these categories project a systematic violation of human rights by the State; various ethical positionings to confront the neoliberalization of social policy and a variety of alternatives to address the deprofessionalization, which responded to the respective ethical positionings of the Social Work professionals. [Keywords: labor conditions, Social Work, professional ethics, ethical-political professional project, human rights].

\section{Introducción}

\section{Neoliberalismo, política social y desprofesionalización del Trabajo Social}

Para Stark (2008), el neoliberalismo consiste en la mercantilización de todos los ámbitos de la vida humana. Es así que se entiende que todo está sujeto a la lógica del mercado y del lucro, incluyendo

\footnotetext{
${ }^{1}$ Trabajador Social. Profesor, Universidad del Este.

${ }^{2}$ Planificador. Director Auxiliar de Planificación, Evaluación y Desarrollo, Departamento de la Familia.

${ }^{3}$ Economista. Asociada en Investigación, Extensión Experimental Agrícola, Universidad de Puerto Rico, Recinto de Mayagüez.

${ }^{4}$ Trabajadora Social. Directora Interina del Programa de Trabajo Social del Negociado de Instituciones Juveniles. Departamento de Corrección y Rehabilitación.

${ }^{5}$ Trabajador Social. Maestro, Departamento de Educación.
} 
a la salud, la vivienda, la educación y la recreación, entre otros. Para el pensamiento neoliberal, el Estado no debe intervenir en la economía más allá de asegurar el espacio necesario para el libre mercado. De esta forma, se fomenta la privatización de las compañías estatales encargadas de suplir los servicios básicos, la desregulación de la economía y el achicamiento del Estado, entre otras estrategias.

De esta forma se sostiene que, bajo la lógica neoliberal, las políticas sociales se pueden articular desde el espacio privado, lo que redunda en la mercantilización de las mismas. Es así que el Estado asume la función de formular y aprobar políticas sociales dirigidas a beneficiar y proteger, fundamentalmente, los intereses particulares del mercado capitalista internacional, asignando solo un mínimo de su presupuesto para palear la pobreza extrema (Laurell, 2004).

Es en el contexto de la neoliberalización de la política social que se da el proceso de desprofesionalización del Trabajo Social. La desprofesionalización es conceptualizada por Benito y Chinchilla (2004) como el "proceso tendiente a descalificar de forma premeditada el rango y competencia profesional. Pretende disminuir paulatinamente las calidades y cualidades que caracterizan a una profesión de formación y trayectoria universitaria" (p. 4). Los autores amplían que dicho proceso:

implica reducir y eliminar las características que hacen de una profesión, precisamente una profesión: metodologías de intervención, conocimientos particulares, presencia de paradigmas epistemológicos y ontológicos que sustentan el cuerpo de conocimientos y la intervención, métodos de investigación de la realidad, capacidad de interpretación, identidad profesional, principios filosóficos y valores éticos, entre otros (p. 4).

López, Barreto y Rivera (2014) destacan cómo dicha desprofesionalización tendrá un impacto negativo, no solo en las condiciones laborales de los profesionales, sino además en la garantía de los derechos humanos de la ciudadanía. Así pues:

...las altas tasas de desempleo, cambios y ambivalencias en los derechos adquiridos de los/as trabajadores/as del país, desaparición y reducción de servicios de atención social, diferentes manifestaciones de violencia, inseguridad física y emocional, aumento del nivel de pobreza y de distancia entre las clases sociales, se resumen a diario en la prensa del país (p. 20).

Además, "poblaciones diversas dependen del Estado en el disfrute de servicios mínimos que atiendan sus derechos 'inalienables', 'inherentes' e 'indivisibles"' (López, Barreto y Rivera, 2014, p. 20). Ante dicho contexto, reafirman la vinculación entre el Trabajo Social y los derechos humanos puntualizando que por un lado, la profesión nace de la lucha por el reconocimiento de los derechos humanos. Por otro, la defensa de los derechos humanos es un eje fundamental de la misma. Sin embargo, al momento también estamos vulnerables al poco acceso y disfrute de los mismos [...], en estos tiempos existen exigencias fundamentales para el Trabajo Social, como sujetar el compromiso de una práctica claramente vinculada a los derechos humanos (López, Barreto \& Rivera, 2014, p. 21).

Al profundizar sobre el impacto de la desprofesionalización de la práctica del Trabajo Social en Puerto Rico, Barreto y López (2013) identificaron:

(a) el impacto que los despidos masivos, a causa de la Ley 7 de $2009^{6}$, tuvo en la carga de trabajo de los y las profesionales de Trabajo Social; (b) como la precarización de los servicios sociales se utiliza como mecanismo para justificar la privatización de los mismos, a la vez que la propia privatización de dichos servicios pudiera encarecer los mismos ya que el gobierno paga por lo más barato, no por la mejor calidad; (c) la preocupación por la calidad de algunos programas de formación en Trabajo Social a los cuales comparan con "fábricas de hacer trabajadores/as sociales"; (d) las divisiones entre la clase profesional que limitan nuestra capacidad para luchar por intereses del propio colectivo; y (e) preocupaciones por el futuro de la profesión y los retos que ésta enfrenta (Barreto \& López, 2013, pp. 4-5).

El estudio citado confirma que en Puerto Rico, al igual que en el resto de los países de la región latinoamericana, se ha ido concretizando la precarización de la política social, y por ende de la práctica del Trabajo Social.

6 Siguiendo la lógica neoliberal, esta ley consistió en reducir el tamaño del gobierno mediante el despido o no renovación de contratos de sobre 30,000 empleados públicos. 


\section{El proyecto profesional como respuesta}

Desde la década del 1990, emergieron en el Trabajo Social latinoamericano diversos debates acerca de lo que se comenzó a denominar como proyecto ético-político profesional. Esto como producto del advenimiento del neoliberalismo y de sus secuelas en el ámbito social, político y económico en los países de la región. Netto (2003) define el proyecto profesional como:

la auto-imagen de una profesión, eligen los valores que la legitiman socialmente, delimitan y dan prioridad a sus objetivos y funciones, formulan los requisitos (teóricos, institucionales y prácticos) para su ejercicio, prescriben normas para el comportamiento de los profesionales y establecen las bases de su relación con los usuarios de sus servicios, con las otras profesiones y con las organizaciones e instituciones sociales privadas y públicas (pp. 274-275).

El autor, al destacar la dimensión política del proyecto profesional, subraya que se posiciona a favor de la equidad y de la justicia social, en la perspectiva de la universalización del acceso a los bienes y servicios relativos a los programas y políticas sociales; la ampliación y la consolidación de la ciudadanía son puestas explícitamente como condición para la garantía de los derechos civiles, políticos y sociales de las clases trabajadoras (Netto, 2003, pp. 289-290).

Es así que "queda claro que el proyecto ético-político del Servicio Social tiene futuro. Y tiene futuro porque apunta precisamente para el combate (ético, político, y práctico-social) al neoliberalismo, para preservar y efectuar los valores que lo informan" (Netto, 2003, p. 293).

En el contexto puertorriqueño, dicho proyecto profesional se ha venido articulando desde el Colegio de Profesionales del Trabajo Social (en adelante Colegio). Dicha organización aprobó en el año 2008 una moción dirigida a aunar los esfuerzos de diversas comisiones para "conformar un proyecto ético-político para el Trabajo Social puertorriqueño que nos permita participar efectivamente en el mejoramiento de nuestras condiciones de trabajo, la defensa de los derechos humanos y la concretización de políticas sociales para la justicia y la equidad" (Colegio, 2008). Siguiendo dicho objetivo, en el año 2011, el Colegio concretizó la Comisión Permanente del Proyecto Profesional, la cual fue ratificada en el 2013 y cuyo principal objetivo consiste en coordinar "los esfuerzos organizativos hacia la construcción de un proyecto profesional pluralista y democrático, dirigidos a alcanzar la justicia social, la equidad y la democracia, posicionando al Colegio como protagonista activo de la sociedad civil" (Colegio, 2013, p. 39).

\section{Finalidad y justificación}

La finalidad principal de esta investigación consistió en examinar estrategias concretas para mejorar las condiciones laborales actuales de los profesionales del Trabajo Social en función de una práctica ética y garante de derechos humanos.

Dicha finalidad se fundamenta en que, al igual que generaciones anteriores de trabajadores y trabajadoras sociales en Puerto Rico hicieron frente a los retos estructurales que se les presentaron, como el establecimiento del estado de bienestar social y la reconceptualización de la práctica ${ }^{7}$, nos toca a la generación de la cual formamos parte el articular e implementar estrategias para afrontar la desprofesionalización del Trabajo Social y sus secuelas en la concretización de los derechos humanos. Consideramos que la investigación que nos propusimos realizar fue un paso en dicha dirección.

\section{Marco teórico}

Este estudio se enmarca en postulados teóricos expuestos por Gergen (1999) respecto a la construcción social de la realidad. Este expone que el mundo se construye a través de las relaciones interpersonales. Desde esta perspectiva teórica, el lenguaje juega un papel protagónico en la construcción de la realidad y del mundo que nos rodea. Gergen (1999) plantea que "para el construccionista, nuestras acciones no están limitadas por nada tradicionalmente aceptado como verdadero, racional o correcto" ( $\mathrm{p}$. 4). Entre sus postulados principales se encuentra el que: (a) el conocimiento no es inductivo; (b) el mismo

7 Consulte a Burgos Ortiz y Seda Rodríguez (2005) y a Guardiola Ortiz y Rivera Rivera (2012) para una discusión detallada sobre el particular. 
es definido por contextos de índole cultural, histórico y social; y (c) el entendimiento y la comprensión del mundo que nos rodea no es un ejercicio natural, en cambio, las condiciones en las que conocemos y comprendemos el mundo que nos rodea obedecen a los intercambios sociales que son enmarcados en tiempo y espacio. El autor nos señala que la manera en que comprendemos y privilegiamos una forma de comprensión sobre otra depende, en gran medida, de los procesos sociales que la contextualizan (Gergen, 2002). Por ello, la manera en que se acuerda o se "negocia" la forma en que comprendemos la realidad está interconectada a otras dimensiones del quehacer social.

En este estudio quisimos explorar cómo los profesionales del Trabajo Social construyen la realidad en referencia a las implicaciones del neoliberalismo en la política social y las alternativas de acción que proponen partiendo de dicha construcción.

\section{Diseño metodológico}

Esta investigación se fundamentó en el paradigma cualitativo. La información que se recopila en estudios cualitativos procede de personas en situaciones y ambientes naturales, cuya interpretación recaerá en última instancia en los significados que tienen los elementos bajo estudio para los propios actores o participantes (Lucca \& Berríos, 2009).

Como diseño metodológico se escogió el estudio de caso. Para la presente investigación se concretizó el caso a investigar como: los procesos necesarios para la superación de las condiciones laborales precarizadas de los y las profesionales del Trabajo Social en Puerto Rico. Como estrategias de recopilación de información se realizaron entrevistas a profundidad y grupos focales.

Las entrevistas realizadas fueron de carácter semiestructuradas-elite. Se emplea el término elite para referirse a participantes de alto renombre en el país, que influyen en la sociedad por los cargos que han ocupado en el ámbito público o privado y que poseen información privilegiada que se considera esencial para la investigación (Lucca \& Berríos, 2009). Para este estudio se entrevistó a Idalia Colón Rondón, secretaria del Departamento de la Familia, entidad gubernamental con la segunda plantilla laboral más grande de trabajadores/as sociales en el país y al presidente del Colegio, Larry E. Alicea Rodríguez.

Además, se efectuaron dos grupos focales que contaron con profesionales del Trabajo Social con práctica en diversos escenarios, tales como: corrección, drogo-dependencia, educación, forense, clínico, independiente, entre otros. En total, participaron diez trabajadores/as sociales en los grupos focales, la mayoría contaba con el grado académico de maestría y tenían una experiencia profesional de entre seis y veinticinco años.

\section{Hallazgos}

Para propósitos de este artículo resaltaremos los discursos que apalabraron las personas participantes sobre tres elementos fundamentales en la consideración de un proyecto ético-político profesional: los derechos humanos, la ética profesional y las estrategias concretas para la superación de la precariedad en la práctica del Trabajo Social. En este ejercicio, seguimos la estructura procedimental del modelo esbozado por Wolcott (1994). El mismo implica un proceso de descripción, análisis e interpretación de los datos cualitativos. La información extraída de las entrevistas y de los grupos focales se estudió para relacionar contenidos y luego reagruparlos para "construir las respuestas a los fines de la investigación" (Lucca \& Berríos, 2009, p. 486). El resultado de agrupar estos contenidos permitió obtener de manera diáfana manifestaciones contextualizadas por las experiencias de las personas participantes.

A continuación se presentan las categorías a priori establecidas para el análisis: (a) vínculo de las condiciones laborales con mi realidad; (b) condiciones laborales precarizadas y derechos humanos; (c) aspiraciones gremiales para mejorar calidad de vida y de la profesión; (d) factores económicos y políticos y precarización de los servicios sociales y las condiciones laborales; (e) acciones del gremio para mejorar condiciones laborales precarizadas; ( $f$ ) retos éticos que superar para concretizar las propuestas; (g) cumplimiento del Colegio con la protección de sus miembros; (h) cumplimiento del Colegio con la ley de colegiación profesional para el mejoramiento de las condiciones laborales; e (i) aspectos más importantes para mejorar las condiciones laborales precarizadas. Para cada categoría se añadieron varias subcategorías que emergieron de las voces de los y las profesionales del Trabajo 
Social participantes.

Subsiguientemente, presentamos los hallazgos del proceso de entrevistas y grupos focales, enfatizando en las categorías que hacen referencia a los derechos humanos, la ética profesional y las estrategias concretas para la superación de las condiciones laborales.

Relación entre las actuales condiciones laborales precarizadas y los derechos humanos

En términos generales las personas participantes reconocieron la existencia de un vínculo inseparable entre las condiciones precarias de la práctica del Trabajo Social y la privación de derechos humanos. De las verbalizaciones de los grupos focales se desprende que el trabajo precarizado se caracteriza por la sobrecarga de tareas y la falta de recursos a nivel institucional para atender las necesidades de la población o canalizar las mismas. Estas adjetivaciones fueron utilizadas relacionándolas con un pobre servicio a la población y que se reconoce atenta contra sus derechos humanos. Además, se identificaron barreras en los procesos de ayuda y el manejo de los casos, las cuales fueron categorizadas como "burocracia gubernamental" y "escasez de recursos" de un "estado que se reduce" o "se privatiza", ante una demanda incremental de servicios sociales. Incluimos una cita que permite ilustrar parte de lo planteado:

donde una compañera trabajadora social tuvo que ir a su casa y buscar una cuna desechable de su bebé para acostar ese bebé en la oficina, donde el lugar donde se tienen que quedar con esos menores para pernoctar en lo que al otro día pueden seguir trabajando casos es un lugar totalmente sin seguridad, unas camas literas, un baño, salida al parking de la oficina, no hay un guardia y ahora ellas se tienen que quedar y comprar de su dinero, comida, ropa, pampers, todo, you name it, que esos niños van a necesitar, más el riesgo que ese trabajador social está incurriendo, está pernoctando y muchas veces el chofer de la oficina se quedaba afuera para velar por la seguridad que ese no es su trabajo (GF1, P9, 411-419).

De forma vinculada, la Secretaria del Departamento de la Familia identificó políticas públicas que fueron adversas a empleados y la población a servir. Indicó la Secretaria que "a raíz de la Ley 7 se perdió el recurso humano", "se despidieron trabajadores sociales que estaban en funciones administrativas", lo cual provocó "un impacto directo en la agencia" (EP2, pp.17-19). Estos elementos fueron mencionados por la mayoría de las personas participantes en sus expresiones sobre la precarización de las condiciones de trabajo y sus consecuencias en la privación de derechos humanos. Por su parte, el presidente del Colegio, describió el vínculo entre las condiciones laborales y los derechos humanos como "transcendental". El presidente añadió que "tiene una relación bien directa porque el mejoramiento de las relaciones laborales de los trabajadores sociales incide sobre las condiciones de las personas", y que "hay una vinculación importantísima entre los mejoramientos de las condiciones laborales de los trabajadores sociales y el mejoramiento de estas personas que generalmente son clases invisibilizadas, marginadas y que somos nosotros los que trabajamos en línea directa con ellos" (EP1, 23-32).

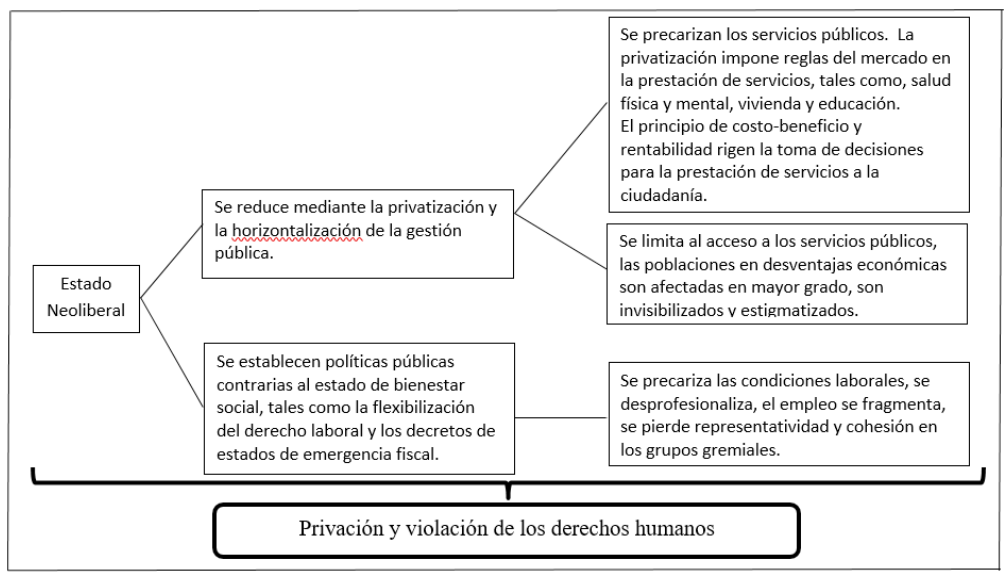

Gráfica \#1. Relación entre las actuales condiciones laborales precarizadas y los derechos humanos según las personas participantes

Ética en las propuestas esbozadas. Bajo esta categoría se obtuvieron diez subcategorías, algunas de estas conflictivas entre sí, ya que respondían a diferentes valoraciones y posicionamientos polarizados 
sobre la práctica y la profesión del Trabajo Social. En esta sección las personas participantes abordaron temas éticos que iban desde: las necesidades económicas versus justicia social, enfrentar las estructuras políticas laborales en defensa de los derechos ciudadanos, abogar por el bienestar del colectivo versus el interés individual, rechazar las presiones político partidistas y enfrentar las críticas de la sociedad. Dentro de los grupos focales, se presentó como necesario reenfocar la práctica del Trabajo Social hacia actividades que brinden beneficios económicos al trabajador/a social. Una de las opciones verbalizadas fue dedicarse a "actividades de investigación y evaluación", explicitando que al profesional del Trabajo Social le era conveniente constituirse en un recurso competitivo mediante la capacitación continua "podemos ser asesores más allá del servicio directo, investigando y evaluando, para eso hay que hacer bien el trabajo. Si quieres mejorar las condiciones laborales necesitas educación continua" (EP2, 53-55), manifestó la secretaria del Departamento de la Familia.

Además, se consideró como un problema ético la justicia salarial. Se criticó a algunos trabajadores/ as sociales que debido a que están en una situación de estabilidad económica, abandonan el reclamo de justicia salarial del colectivo: "hay trabajadores sociales en posiciones en agencias federales, en las mismas agencias públicas en posiciones de autoridad que probablemente se han desvinculado, por la práctica independiente puede ser o colegas en asesoramiento de políticas sociales en la Legislatura, pero al estar bien pagos pichean. Aquí es un asunto que debe ser el colectivo" (EP1, 164-178), expresó el presidente del Colegio. El mejorar las condiciones laborales, ya no solamente en su base salarial, sino además en asuntos de seguridad ocupacional y personal fue otro planteamiento que se contrastó con el contenido del Código de Ética, indicando que "un principio esencial del mismo" es mejorar las condiciones laborales. La siguiente cita ejemplifica no solo la base filosófica de la ética en la profesión del Trabajo Social, sino además la cruda realidad de las condiciones bajo las cuales se ejerce la profesión.

... es justicia social el conseguir mejorar las condiciones laborales porque estamos en condiciones laborales precarias y hacinadas. Los colegas de Puerto Rico en el estudio de condiciones laborales que se hizo en conjunto con la Escuela Graduada ${ }^{8}$, con la COLACATS ${ }^{9}$ y el Colegio, reveló que en Puerto Rico trabajadores sociales están trabajando en lugares de alto riesgo para su seguridad por encima de Colombia, de colegas en zonas armadas. O sea que, eso esboza que realmente es un asunto de justicia social, principio esencial de nuestro Código de Ética (EP1, pp. 152-159).

Finalmente, se presentó el problema del partidismo político, y se señaló cómo este ha ido penetrado la práctica profesional, afectando la justicia social en la prestación de servicios.

\section{Acciones del gremio para mejorar condiciones laborales}

Bajo esta categoría surgieron unas diez subcategorías que representan propuestas concretas verbalizadas tanto en los grupos focales como en las entrevistas. Estas propuestas destacan la necesidad de representación sindical, la educación y la investigación, el empresarismo, la inserción en los medios de comunicación, el aumento de la militancia y la identidad profesional, y el involucrarse en el desarrollo de políticas públicas. En uno de los grupos focales se consensó que ante la realidad social y económica del país es necesario "algún tipo de representación sindical" (GF1, P5, 262-265). Apalabraron ver "francamente la necesidad y más nosotros en área escolar de tener nuestro propio sindicato que podamos entonces dirigirnos a defendernos" (GF1, P5, 1356-1361). Este sindicato tendría funciones especiales tales como la de educar la matrícula y estaría libre de ataduras político partidistas, "visualizo un sindicato que conozca las necesidades de educación, de especialización de cada área y no una vez al mes sino frecuentemente vaya educando a todos esos trabajadores sociales y se asegure que su matrícula sea la más especializada en términos de todas la materias que exista en Puerto Rico que nos van a representar a nivel de Puerto Rico. No visualizo en ese sindicato nada que tenga que ver con lo político partidista" (GF1, P7, 1515-1524).

La educación fue un factor importante para las personas participantes de los grupos focales. Propusieron que el profesional del Trabajo Social se mantenga actualizado mediante la educación

\footnotetext{
${ }^{8}$ Escuela Graduada de Trabajo Social de la Universidad de Puerto Rico.

${ }^{9}$ Comité Latinoamericano y Caribeño de Organizaciones Profesionales de Trabajo Social
} 
continua y que de igual modo, al nivel del bachillerato, el profesorado se actualice para que dicten cursos que estén alineados a la realidad contemporánea. Según lo expresado, la investigación es otro elemento de pertinencia. Señalaron que era necesario que no solo se investigue, sino además que se comparta ese conocimiento nuevo para el enriquecimiento de la profesión. Manifestaron que la investigación puede servir para concienciar sobre las condiciones laborales en el Trabajo Social y mejorar la imagen de la profesión. La siguiente cita abunda sobre este planteamiento:

Esto que ustedes están haciendo es una de ellas [en referencia a la investigación que se realizaba], porque de alguna manera sabemos que existen los problemas, sabemos que estas son las condiciones, pero todavía yo tengo gente, colegas míos que no entienden esto, y entonces hay que crear conciencia en el mismo grupo, hay que ser portavoces, y una manera de ser portavoces es investigando, divulgando lo que se investigó, estableciendo diferentes campañas, por eso es que horita yo dije, yo creo que la profesión, voy a utilizar la palabra posicionarse, está haciendo cosas y como grupo podemos hacer cosas que nos van a dar una imagen distinta, pero no puede ser un grupo pequeño, tenemos que lograr impactar a todos nuestros..., o sea, si yo estoy aquí yo tengo que tratar de transmitir este mensaje a todos mis compañeros, y que entiendan que esto es importante, y que entiendan que tienen que estar ahí para que entonces realmente podamos tener unas condiciones distintas, que podamos pelearlas, que las podamos luchar (GF2, P3, 561-571).

La posibilidad de proveer servicios de consultoría, asesoramiento y crear organizaciones fueron propuestas presentadas por la secretaria del Departamento de la Familia como alternativas: "con apertura, hay que atreverse a abrir los espacios. Es ver cómo diversificar la profesión, diseñando modelos. Es importante más allá del servicio directo, es asesorar, evaluar, desarrollar políticas", "como trabajador social puedes ser un empresario exitoso. Se pueden organizar en una corporación y atender las necesidades apremiantes". (EP-2, 51-52; 61-62). Se identificó, además, una institución académica que había dado un giro en la tradición filosófica del Trabajo Social hacia uno de carácter empresarial, "esta universidad está empezando a formar trabajadores sociales en lo que son los business, esto, empresas, grandes empresas y en negocios" (GF1, P9, 1460-1463). De forma vinculada, al destacar aspectos relacionados al empresarismo, se apalabró "desde el 2005 trabajando por mi cuenta y mi visión antes no era así. Yo salí de la universidad pensando que tenía que irme a trabajar en una agencia porque nos preparan hacia eso. Cuando yo me fui de una agencia de gobierno la gente me decía, 'tú eres loca, esto te vas, esto es un empleo seguro", (GF1, P9, 1460-1467).

Entre otras estrategias, se identificó que la inserción en los medios de comunicación sería una herramienta útil de propósito dual que permitiría dar a conocer las condiciones precarias de la práctica profesional, por un lado, y el por el otro serviría para dar a conocer qué es el Trabajo Social y su importancia para la sociedad. Además, la organización del gremio y la militancia para el reclamo de mejoras en las condiciones laborales son áreas de trabajo que requieren atención, según los participantes. De otra parte, se percibió, a raíz de las diversas verbalizaciones, opiniones divergentes en relación al nivel de satisfacción con el Colegio en términos de la representatividad. Sin embargo, en paralelo, se percibe un nivel bajo de participación de los colegiados en las actividades del Colegio. Hubo alegaciones en el sentido de las actividades para el desarrollo profesional representan un costo adicional al costo de colegiación. La colaboración fue descrita como una "falta de militancia", lo cual se traduce a una participación diezmada en las actividades del Colegio. Luego, se identificó la percepción de algunos de los participantes respecto a que el Colegio "está distante" a sus reclamos.

A continuación, se ilustran expresiones de visiones contrarias sobre la participación de los/as profesionales del Trabajo Social en el Colegio: "lo que pasa es que no tenemos militancia. Es poca la militancia que tenemos, entonces esa falta de militancia se traduce en que el proyecto del colectivo se vea como el proyecto de unos pocos, como el proyecto de la Junta Directiva", "entonces la gente no ha vinculado el mejoramiento de sus condiciones laborales a la militancia del colectivo, entonces lo delegan en el Colegio" (EP1, 58-65). Desde el ángulo contrario, la siguiente expresión es una crítica fundamentada en la percepción de una de las participantes: "pero mi percepción siempre ha sido del Colegio sinceramente como una entidad social", "son los encargados de la educación sin embargo tengo 
que pagar por la colegiación y encima de eso pues tengo que pagar por la educación y encima de eso si quiero ir a la actividad social también tengo que pagar" (GF1, P7, 1216-1218).

Además, se presentó como alternativa un nivel más participativo del profesional de Trabajo Social en la política social, lo cual incluiría la consideración de utilizar cabilderos a favor de esta profesión en la Legislatura. La siguiente cita representa el consenso sobre el tema verbalizado en uno de los grupos focales "el análisis y las evaluaciones deberían añadirse sí, porque lo que se nos ha hecho difícil entender, el Trabajo Social surge desde el punto de vista de la política social' (GF1, P5, 1611-1615).

Tabla \# 1

Acciones concretas del gremio para superar condiciones laborales precarizadas

\begin{tabular}{|c|c|c|c|c|c|}
\hline Sindicalismo & $\begin{array}{c}\text { Educación, } \\
\text { Investigación y } \\
\text { divulgación }\end{array}$ & Empresarismo & $\begin{array}{l}\text { Desarrollo de } \\
\text { la identidad } \\
\text { profesional }\end{array}$ & $\begin{array}{c}\text { Inserción en la } \\
\text { discusión pública }\end{array}$ & $\begin{array}{c}\text { Militancia y } \\
\text { activismo }\end{array}$ \\
\hline $\begin{array}{l}\text { Representación } \\
\text { sindical } \\
\text { Colegio más } \\
\text { enfocado } \\
\text { en aspectos } \\
\text { sindicales } \\
\text { Sindicatos que no } \\
\text { estén atados a } \\
\text { ideologías político } \\
\text { partidistas }\end{array}$ & $\begin{array}{l}\text { Educación continua } \\
\text { Fortalecer la facultad } \\
\text { en programas de } \\
\text { Bachillerato } \\
\text { Desarrollar } \\
\text { investigaciones y } \\
\text { divulgar hallazgos }\end{array}$ & $\begin{array}{c}\text { Crear } \\
\text { corporaciones } \\
\text { Autoempleo } \\
\text { Consultoría }\end{array}$ & $\begin{array}{c}\text { Inserción en } \\
\text { los medios de } \\
\text { comunicación } \\
\text { Fortalecer la } \\
\text { identidad profesional } \\
\text { Hacer que se oiga } \\
\text { la voz }\end{array}$ & $\begin{array}{l}\text { Cabildeo a favor de } \\
\text { la profesión en la } \\
\text { Legislatura } \\
\text { Desarrollar políticas } \\
\text { sociales } \\
\text { Evaluar la política } \\
\text { pública }\end{array}$ & $\begin{array}{l}\text { Organización } \\
\text { profesional } \\
\text { Participación en } \\
\text { el Colegio } \\
\text { Desarrollo de } \\
\text { un conclave }\end{array}$ \\
\hline
\end{tabular}

\section{Discusión}

El análisis de las verbalizaciones recopiladas nos permitió comprender y profundizar en las nociones que las personas participantes tienen sobre la práctica profesional en el contexto de la neoliberalización de la política social y las diversas estrategias para hacerle frente a dicho contexto social y laboral.

Las expresiones de los/as profesionales participantes dieron cuenta de cómo el Estado, de forma sistemática, no viabiliza los derechos humanos de la ciudadanía. Esto toma forma mediante la prestación de unos servicios sociales precarios, los cuales no garantizan la satisfacción de necesidades básicas. Por ejemplo, en cuanto a la violación de los derechos humanos, vemos como una de las participantes adujo que en

el Departamento de la Familia los niños tienen derecho a la seguridad, pero si tú haces un referido de una sospecha de un abuso sexual y ese caso no se ve en un año, tú estás violentando ese derecho a la seguridad de ese niño, se reduce a eso, es tan simple como eso, y digamos un ejemplo, tienen a ancianos que viven solos en condiciones precarias y lograr que el Departamento de la Familia te apruebe fondos para pagar un hogar de cuidado prolongado a ese anciano es una lucha cuesta arriba (GF1, P9, 525-530).

Las expresiones de los/as participantes legitiman la exhortación de Barreto Cortez (2010), quien arguye que:

la práctica profesional en nuevos espacios y la defensa de los derechos humanos y las políticas sociales, podrán ser instancias posibles necesarias de nuestra acción profesional, pues no nos queda otra alternativa que defender nuestros espacios actuales de trabajo y el ofrecimiento de suficientes servicios de calidad, así como de ocupar nuevos espacios con el mayor grado de integridad posible (p. 64).

De esta manera, la autora nos convoca a los/as profesionales del Trabajo Social a enfrentar la neoliberalización de los servicios de bienestar social de forma activa, no solamente debido a que su precarización atenta contra nuestras condiciones labores, sino porque va en detrimento de la integridad física y sicológica de las poblaciones más vulnerables en el país, quienes se ven desprovistos de servicios profesionales que les permitan satisfacer sus necesidades fundamentales.

Otro aspecto que amerita una profunda reflexión de parte de la clase profesional lo constituye 
los fundamentos éticos desde los cuales los/as trabajadores/as sociales estamos partiendo para hacerle frente a la neoliberalización de los servicios sociales. Cabrera Cirilo (2012) expone que la ética profesional del Trabajo Social en Puerto Rico se originó con un enfoque cristiano conservador, el cual presenta la filantropía como principio rector. El autor repudia dicho enfoque y propone que la ética profesional parta de un análisis crítico de la realidad social. De forma vinculada, Silva Barroco (2004) indica que no podemos estar satisfechos con una ética desvinculada de los derechos humanos, que naturalice la pobreza en las relaciones de clases, que generalice o se abstraiga de los problemas cotidianos en el ejercicio de la profesión.

Sin embargo, del análisis de las verbalizaciones se desprenden diversos discursos respecto a en qué valores se debería fundamentar la ética profesional en el contexto de la neoliberalización de la política social. Mientras unos/as profesionales señalaban la necesidad de mercantilizar sus servicios profesionales mediante la venta de los mismos bajo la lógica del sistema neoliberal, otros/as esbozaban la indispensabilidad de, éticamente, siempre estar posicionados/as a favor de las clases marginadas, lo cual implicaba el que el Estado garantice la prestación de los servicios sociales, independientemente del poder adquisitivo de las personas que necesitaran de los mismos.

Posicionándose en un fundamento ético que validaba la mercantilización de los servicios sociales, una de las participantes apalabró que

el pensamiento del trabajador social tiene que empezar a pensar en eso también, en que ya no somos meramente Robin Hoods, tenemos que pensar un pensamiento que tenemos que ganar dinero, y que tienes que abrirte a otros campos, no solamente a la justicia social y todas esas cosas (GF1, P9, 155-158).

Mientras, otro profesional argüía la premisa de que el Trabajo Social debía siempre estar dirigido a favor de los sectores sociales marginalizados, no dando paso a posicionamientos que se alejaran de dicha premisa.

Esta profesión tiene tantos y tantos debates que son totalmente innecesarios que yo no entiendo, ¿dónde tú estás posicionado políticamente?, ¿con los que tienen o con los que no tienen?, bueno con los que no tienen. ¿Por qué vas a estar posicionado con los que tienen que están oprimiendo? Esos son debates que no hacen sentido que se tengan, aquellos que están en posición neutral "que yo estoy a favor de todo", pero si es obvio que, número uno, es tu trabajo, número dos, es lo que te afecta a ti en tu manera individual, número tres, no hace falta que nadie tenga más de lo que necesita para vivir. O sea, son debates bien simples, y muchos otros, pero estamos afanados en debates que podemos posicionarnos tranquilamente como trabajador social y es cónsono con la profesión y hacer lo contrario es totalmente contrario a la profesión (GF2, P4, 631-640).

Sobre el debate en cuanto a los fundamentos de la ética profesional apalabrados durante los grupos focales y las entrevistas realizadas, López, Barreto y Rivera (2014) nos invitan a considerar que pensar que "en la gestión individual, el ejercicio liberal de la profesión y el "sálvese quien pueda" está la solución a nuestros dilemas profesionales, es andar por el camino de desarraigar la profesión de su vínculo con los derechos humanos que tantas luchas y vidas costaron" (p. 40).

El hecho de que el debate ético arriba detallado haya sido una de las principales preocupaciones planteadas a lo largo de los grupos focales y las entrevistas realizadas, nos debe llevar a considerar la necesidad de seguir abriendo espacios profesionales que nos permitan seguir profundizando sobre las implicaciones de los mismos.

En lo que concierne a la organización de la clase profesional, esta fue una de las principales estrategias para superar las condiciones precarizadas esbozadas por las personas participantes de la investigación. Hubo un reclamo repetitivo respecto a que se debía aspirar a la unidad de la clase profesional "que todos nos tenemos que unir, que tenemos que dejar de pensar que aquello es aparte, que somos casitas diferentes, porque todos ofrecemos un servicio que es dirigido a alcanzar la equidad social en nuestro país" (GF1, P3, 1554-1556). Sin embargo, este reclamo vino acompañado de marcadas críticas al Colegio fundamentadas en una alegada ausencia del organismo en espacios sociales que debería estar ocupando, "tienes que criticar pero debes estar dispuesto a colaborar. El Colegio debe estar posicionado en todos los sectores. Más que criticar deben apoyar, que estén presentes en las 
juntas y los concilios y en los otros diversos ámbitos" (EP2, 100-103).

Cuando contrastamos las expresiones respecto a la necesidad de la organización profesional como mecanismo para superar la precarización con lo establecido en la literatura, vemos una fuerte coincidencia con autores como Netto (2003), quien destaca que

la experiencia socio-profesional ha comprobado que para que un proyecto profesional se afirme en la sociedad, gane solidez y respeto frente a las otras profesiones, las instituciones privadas y públicas, y aún más, frente a los usuarios de los servicios ofrecidos por la profesión, es necesario que tenga en su base un colectivo fuertemente organizado (p. 275).

Mientras, Barreto Cortez (2010) enfatiza en la necesidad de que "junto a colegas de Trabajo Social, de otras profesiones y de las propias personas participantes de los servicios, podemos organizarnos para defender, mejorar y expandir dichas políticas sociales y los derechos sociales que las cobijan" ( $p$. 64). Ante esto, entendemos que el Colegio debe continuar teniendo entre sus principales prioridades el fortalecimiento de sus diversos organismos (comisiones, capítulos y junta directiva) mediante una participación significativa en términos numéricos y diversos ideológicamente. Esto, procurando establecer vínculos con otros grupos profesionales y de la sociedad civil que también aspiren a combatir los postulados y secuelas de la política y economía neoliberal.

Finalmente, en lo que concierne a la concretización del Proyecto Profesional que se viene articulando en el Colegio desde el año 2008, entendemos pertinente retomar las reflexiones esbozadas por una de las trabajadoras sociales más influyentes y pionera de la práctica profesional del Trabajo Social puertorriqueño. Carmen Rivera de Alvarado (1973), hace cuatro décadas atrás, ya nos invitaba a reflexionar respecto a que,

el despertar de los pueblos del Tercer Mundo y de las masas oprimidas y explotadas de los grandes poderíos industriales, colocan el Trabajo Social frente a una encrucijada que exige, no solo una reconceptualización de sus valores, funciones, métodos y objetivos, sino también acción concertada y dedicada como grupo profesional (p. 158).

Además, añadía lo siguiente:

la profesión de Trabajo Social está en uno de esos momentos culminantes en que tiene necesariamente que definir su posición en la sociedad. ¿Continuará atada a su tradición conservadorista o estará dispuesta a asumir posiciones radicales frente a los problemas que afligen a las sociedades modernas? ¿Mantendrá su posición elitista de clase media o estará en disposición de vivir en la práctica lo que enseña en la teoría: la esencial igualdad del ser humano? ¿Se mantendrá como institución aislada, desconectada del pueblo o se unirá a otros grupos de avanzada como fuerza revolucionaria en solidaridad con las clases oprimidas? ¿Estará dispuesta a comprometerse? (p. 158).

Son estos cuestionamientos, articulados hace cuatro décadas, los que a nuestro juicio deben servir como brújula en el proceso de desarrollo y concretización de nuestro Proyecto Profesional. El combatir con fuerza y entereza la desprofesionalización del Trabajo Social es un asunto que trasciende los derechos laborales. Se trata de garantizar que un niño abusado sexualmente tendrá los servicios que necesita para superar al quebrantamiento de su integridad en un periodo adecuado; se trata de asegurarnos que la persona con dependencia a drogas podrá recibir los servicios que amerite para escapar de dicha esclavitud y recuperar su vida. Se trata, como postula la Escuela Graduada de Trabajo Social de la Universidad de Puerto Rico, de garantizar "una sociedad justa, equitativa y libre de opresión".

Ante esto, añadimos a los cuestionamientos esbozados por Rivera de Alvarado (1973): ¿será capaz esta generación de trabajadores/as sociales de hacerle frente, de forma coordinada y coherente, a la trasgresión de los derechos humanos de las poblaciones más vulnerables de nuestra sociedad, producto de la neoliberalización de los servicios sociales?, ¿estaremos dispuestos/as a asumir las consecuencias que implica retar el actual e inhumano sistema político-económico neoliberal?, ¿seremos dignos/as de ser citados/as, de aquí a cuarenta años, sirviendo como referente a futuras generaciones de colegas en el proceso de asumir los retos contextuales que a ellos/as les toque lidiar? Los cuestionamientos y el sendero ya están planteados, sólo nos falta contestar, ¿los asumiremos? 


\section{Recomendaciones}

Partiendo de los hallazgos del presente estudio, recomendamos al Colegio: (a) darle continuidad al proyecto profesional que se ha estado desarrollando, focalizando en aspectos vinculados con la organización de la clase profesional; (b) generar espacios de reflexión dirigidos a pensar la ética profesional más allá del Código, enfatizando en cómo se debe ejercer la profesión en el actual contexto neoliberal y las implicaciones de ello; (c) que la Comisión de Proyecto Profesional estudie y analice las múltiples propuestas esbozadas por las personas participantes respecto a estrategias concretas para superar la precarización de las condiciones laborales del Trabajo Social; y que, (d) partiendo del presente estudio, se generen otras investigaciones dirigidas a profundizas en aspectos vinculados al proyecto profesional, la ética profesional y los derechos humanos.

\section{Referencias}

Barreto Cortez, Esterla. (2010). Reflexiones acerca de la construcción de un proyecto ético-político profesional. Análisis, XI (1), 49-67.

Barreto Cortez, Esterla, \& López Ortiz, Mabel. (2013). Condiciones laborales de los y las profesionales de Trabajo Social. Puerto Rico: Colegio de Profesionales del Trabajo Social de Puerto Rico.

Benito, Luisa, \& Chinchilla, Marcos. (2004). Flexibilización laboral y desprofesionalización del Trabajo Social. Ponencia presentada en el XVIII Seminario Latinoamericano de Escuelas de Trabajo Social. San José, Costa Rica.

Burgos Ortiz, Nilsa, \& Seda Rodríguez, Raquel (2005). Reflexiones en torno al Movimiento de Reconceptualización del Trabajo Social en Puerto Rico. En N. Alayón (Ed.), Trabajo Social Latinoamericano: a 40 años de la Reconceptualización. Buenos Aires: Espacio Editorial.

Cabrera Cirilo, Jesús. (2012). Apuntes para fundamentar un proyecto ético-político profesional en Puerto Rico. Voces desde el Trabajo Social, I(1), 41-42.

Colegio de Profesionales del Trabajo Social de Puerto Rico. (2008). Resolución número 5 de 2008 a los fines de fomentar la participación ciudadana. San Juan, Puerto Rico: Autor.

Colegio de Profesionales del Trabajo Social de Puerto Rico. (2013). Reglamento del Colegio de Profesionales del Trabajo Social de Puerto Rico. San Juan, Puerto Rico: Autor.

Gergen, Kenneth. (1999). An invitation to social construction. London: Sage.

Gergen, Kenneth. (2002). El movimiento del Construccionismo Social en la psicología moderna. Recuperado en http://www. comminit.com/la/node/149894

Guardiola Ortiz, Dagmar, \& Rivera Rivera, Antonia. (2012). El Trabajo Social en Puerto Rico. En M. C. Melano \& J. P. Deslauriers (Coords.), El Trabajo Social Latinoamericano: elementos de identidad (pp. 267-293). Argentina: LumenHvmanitas.
Laurell, Asa Cristina. (2004). Avanzar al pasado: la política social del neoliberalismo. En Elizabeth Borgianni y Carlos Montaño (Eds.), La política social hoy (2da ed.) (pp. 233-259). Brasil: Cortez Editora.

López Ortiz, Mabel; Barreto Cortez, Esterla, \& Rivera Ortega, Jessenia. (2014). Derechos humanosy condiciones laborales del Trabajo Social en Puerto Rico: asuntos medulares en la construcción del Proyecto Profesional del Colegio de Profesionales del Trabajo Social de Puerto Rico. Voces desde el Trabajo Social, 2(1), 13-44

Lucca Irizarry, Nydia, \& Berríos Rivera, Reinaldo. (2009). Investigación cualitativa: Fundamentos, diseños y estrategias. Puerto Rico: Ediciones $\mathrm{SM}$.

Netto, Jose Paulo. (2003). La construcción del proyecto ético-político del servicio social frente a la crisis contemporánea. En Elizabeth Borgianni, Yolanda Guerra \& Carlos Montaño (Eds.), Servicio Social Crítico: hacia la construcción del nuevo proyecto-ético-político profesional. (pp. 272-275, 289-290, 293). Brasil: Cortez Editora.

Rivera de Alvarado, Carmen. (1973). El Trabajo Social: Una profesión en la encrucijada. En Trina Rivera de Ríos (Ed.), Carmen Rivera de Alvarado: Lucha visión de Puerto Rico libre. (p. 158). Fundación Carmen Rivera de Alvarado y J. Antonio Alvarado. República Dominica.

Silva Barroco, María L. (2004). Ética y Servicio Social: Fundamentos ontológicos Sao Paulo: Cortez Editora.

Stark, Christian. (2008). Neoliberalism and the Consequences for Social Work. The Journal of Social Work: Theory and Practice, 17(4).

Wolcott, Henry. (1994). Transforming qualitative data: Description analysis, and interpretation. Thousand Oaks, CA: Sage 